\title{
Do we differ in terms of indications and demographics in cardiac resynchronisation recipients in Poland? Insights from the European CRT Survey II Registry
}

\author{
Damian Łasocha ${ }^{1 *}$, Maciej Sterliński ${ }^{1 *}$, Mateusz Tajstra², Krystian Josiak ${ }^{3}$, Dariusz Zając ${ }^{4}$, \\ Sławomir Tłuczek ${ }^{5}$, Adam Sokal ${ }^{6}$, Łukasz J. Januszkiewicz ${ }^{7}$, Bogdan Galar ${ }^{8}$, Rafał Sznajder ${ }^{9}$, \\ Jarosław Kaźmierczak ${ }^{10}$, Łukasz Szumowski ${ }^{1}$, Camilla Normand ${ }^{11}$, Cecilia Linde ${ }^{12}$, Kenneth Dickstein ${ }^{11}$ \\ 'Department of Arrhythmia, Institute of Cardiology, Warsaw, Poland \\ ${ }^{2} 3^{\text {rd }}$ Chair and Department of Cardiology, SMDZ in Zabrze, Silesian Centre for Heart Diseases, \\ Medical University of Silesia, Katowice, Poland \\ ${ }^{3}$ Department of Heart Diseases, Wroclaw Medical University, Wroclaw, Poland \\ ${ }^{4} 2^{\text {nd }}$ Department of Coronary Artery Disease, Institute of Cardiology, Warsaw, Poland \\ ${ }^{5}$ Faculty of Medicine, University of Rzeszow, Rzeszow, Poland \\ ${ }^{6}$ Department of Cardiology, Congenital Heart Diseases, and Electrotherapy, Silesian Centre for Heart Diseases, \\ Medical University of Silesia, Zabrze, Poland \\ ${ }^{7} 1^{\text {st }}$ Chair and Department of Cardiology, Medical University of Warsaw, Warsaw, Poland \\ ${ }^{8}$ Department of Cardiology, Hospital of the Ministry of Internal Affairs, Bialystok, Poland \\ ${ }^{9}$ Department of Electrocardiology, Upper Silesian Medical Centre of the Silesian Medical University, Ochojec, Poland \\ ${ }^{10}$ Department of Cardiology, Medical University, Szczecin, Poland \\ ${ }^{11}$ Cardiology Division, Stavanger University Hospital, Stavanger, Norway \\ ${ }^{12}$ Heart and Vessels Theme, Karolinska University Hospital, Stockholm, and Karolinska Institute, Stockholm, Sweden \\ *Both authors equally contributed to the study.
}

\section{A bstract}

Background: Multiple randomised clinical trials have proven that cardiac resynchronisation therapy (CRT) reduces morbidity and mortality in appropriately selected patients with congestive heart failure and is recommended for such patients as per the European Society of Cardiology guidelines.

Aim: In this paper we compare the indications and demographics in cardiac resynchronisation recipients in Poland and other European countries.

Methods: In 2015 and 2016, physicians from 42 European countries participated in the second edition of the European Cardiac Resynchronisation Therapy Survey. For 14 months, 288 implanting centres gathered data regarding demography, indications, implanting methods, and guidance compatibility from 11,088 patients receiving CRT.

Results: The survey revealed that a vast group of patients were eligible for CRT implantation (although some of them with relatively weak guidance recommendations) and showed essential variety in clinical practice when national data were benchmarked. Conclusions: The population of CRT recipients in Poland and other European countries did not differ in terms of demographic and clinical characteristics. In most cases, indications for CRT were in accordance with the guidelines; however some devices were implanted in patients beyond the guideline recommendations. For these procedures, the decision regarding CRT implantation relies mainly on the physicians' experience.

Key words: cardiac resynchronisation therapy, chronic heart failure, survey

Kardiol Pol 2019; 77, 1: 40-46

Address for correspondence:

Damian Łasocha, MD, Department of Arrhythmia, The Cardinal Wyszynski Institute of Cardiology, ul. Alpejska 42, 04-628 Warszawa, Poland, tel: +48 22 3434417, fax: +48 22 3434520, e-mail: lasocha.damian@gmail.com

Received: 15.08.2018 Accepted: 7.11.2018

Available as AoP: 7.11.2018

Kardiologia Polska Copyright (C) Polish Cardiac Society 2019 


\section{INTRODUCTION}

The incidence of heart failure (HF) approaches five to ten cases per 1000 people per year, and the prevalence can be estimated as $1 \%$ to $2 \%$ of the adult population in developed countries, rising to $10 \%$ among people over 70 years of age [1, 2]. Throughout the last decades, advancements in therapies and their implementation have improved survival and reduced the hospitalisation rate in patients with congestive heart failure (CHF). One of the treatments, cardiac resynchronisation therapy (CRT), supports cardiac performance in appropriately selected patients, improves symptoms and well-being, and reduces morbidity and mortality [3]. A total of 14 randomised clinical trials (RCTs), involving 4420 patients proved that CRT decreased hospitalisation by $37 \%$ and all-cause mortality by $22 \%$ [4].

In 1994, Serge Cazeau, a cardiologist at Val d'Or Surgical Centre in St. Cloud, France, implanted the first four-chamber pacing device in a patient with severe CHF [5]. In 2005 CRT was included in the European Society of Cardiology (ESC) guidelines. Since 2011, every year the average CRT implantation rate in western and central Europe was approximately 140 units per million population, with an advantage of CRT-defibrillators (CRT-D) over CRT-pacemakers (CRT-P) [6]. In Poland, since Professor Kutarski implanted the first CRT in 1998, the method has evolved rapidly, reached an important position and was a subject of multiple observations [7].

The aim of CRT is to restore atrioventricular as well as inter- and intraventricular synchrony via three leads positioned in the right atrium, right ventricle (RV), and left ventricle (LV) through the coronary sinus tributary.

Continuous biventricular pacing prevents blockade in the cardiac conduction system. CRT improves the LV function, reduces functional mitral regurgitation, and induces $L V$ reverse remodelling, as shown by an increase in LV filling time and left ventricular ejection fraction (LVEF) and a decrease in LV end-diastolic and end-systolic volumes, mitral regurgitation, and septal dyskinesis [8].

Combined data of sub-groups of patients from the COMPANION, CARE-HF, MADIT-CRT, REVERSE, and RAFT trials proved that CRT is most beneficial to symptomatic patients (New York Heart Association [NYHA] class II-IV) with complete left bundle branch block (LBBB), QRS duration $\geq 150 \mathrm{ms,}$ and severely depressed LVEF $\leq 35 \%$ [6]. Therefore, the current guidelines give strong recommendations for CRT in such patients, who do not respond sufficiently to medical therapy.

In 2015, two ESC Associations, the European Heart Rhythm Society (EHRA) and the Heart Failure Association (HFA), formed the European Cardiac Resynchronisation Therapy Survey II, a 15-month initiative (from October 2015 to December 2016) designed to collect a large volume of clinical and demographic data on the delivery of CRT in European countries $[9,10]$. In this paper we present the main differences between the CRT recipients in Poland and other European countries.

\section{METHODS}

Thanks to the efforts of medical teams from 288 centres, the survey gathered data from 42 countries involving 11,088 patients and provided information permitting centres and countries to benchmark their practice with international practice.

After providing general information on the implanting centre (facility type, size, operator speciality), each hospital was asked to complete an electronic case report form on consecutive patients who were referred for CRT implantation [11]. The electronic case report form collected data on patients' characteristics, examinations, indications for CRT, implantation procedures, and short-term outcome including adverse events and complications. Information on longer-term outcome was not collected.

The survey was created to investigate only new CRT implantations (either CRT-P or CRT-D), including both successful and unsuccessful procedures. This also included upgrades from previously implanted cardioverter-defibrillators (ICDs) or permanent pacemakers.

Poland provided essential data on 1241 patients with CRT, which comprised $11.2 \%$ of the whole survey group. In the present study, Polish patients were compared with the control group of 9847 patients from all other participating countries in terms of each available demographic and procedural parameter.

Ethical approval and written, informed consent were obtained according to the rules for clinical investigations in each participating country at the initiation of the study.

\section{Statistical analysis}

Absolute numbers and percentages were shown for categorical variables to describe the patient population, and means (with standard deviations) or medians (with interquartile range) were used for continuous variables. Categorical variables were compared between subgroups by the $\chi^{2}$ test and continuous variables (numerical values) by the Mann-Whitney-Wilcoxon test.

A significance level of $p<0.05$ was assumed for the statistical tests. All statistical analyses were performed using SAS statistical software (version 9.1, Cary, NC, USA).

\section{RESULTS}

A total of 1192 devices were implanted in Poland, with an advantage of CRT-Ds (87\%) over CRT-Ps (13\%). In 69.4\% of patients receiving CRT-D the clinical indication for the implantation was CHF with wide QRS. On the other hand, $70.3 \%$ of patients referred for CRT-P had a pacemaker indication with an expected high percentage of RV pacing. The main differences between CRT-D and CRT-P subgroups are presented in Table 1. In Poland, the mean age of the patients was $67.7 \pm 9.7$ years compared to $68.6 \pm 10.9$ years in all other countries (median 68 and 70 years, respectively, $\mathrm{p}<0.00001$ ). The majority of patients receiving CRT were 
Table 1. Characteristics of cardiac resynchronisation therapy-defibrillator (CRT-D) and cardiac resynchronisation therapy-pacemaker (CRT-P) recipients in Poland

\begin{tabular}{|lccc|} 
& CRT-D $(\mathbf{n}=\mathbf{1 1 3 7})$ & CRT-P $(\mathbf{n}=115)$ & $\mathbf{p}$ \\
\hline Mean age [years] & $66.6 \pm 9.3$ & $74.7 \pm 9.7$ & 0.00001 \\
Male/female sex & $81.7 / 18.3$ & $77.4 / 22.6$ & 0.19893 \\
Atrial fibrillation & 40.8 & 57.4 & 0.00010 \\
Previous pacemaker implantation & 8.2 & 36.1 & $<0.00001$ \\
Previous ICD implantation & 18.2 & 0 & $<0.00001$ \\
\hline
\end{tabular}

Data are shown as mean \pm standard deviation or percentage. ICD — implantable cardioverter-defibrillator

Table 2. History of patients with ischaemic heart failure

\begin{tabular}{|lccc|} 
& $\begin{array}{c}\text { Poland } \\
(\mathbf{n}=\mathbf{1 2 4 1})\end{array}$ & $\begin{array}{c}\text { Other countries } \\
(\mathbf{n}=\mathbf{9 8 4 7})\end{array}$ & $\mathbf{p}$ \\
\hline Myocardial infarction & 48.4 & 34.7 & $<0.00001$ \\
Prior revascularisation (PCI/CABG) & 51.2 & 37.3 & $<0.00001$ \\
\hline
\end{tabular}

Data are shown as percentage. CABG — coronary artery bypass grafting; $\mathrm{PCl}$ - percutaneous coronary intervention

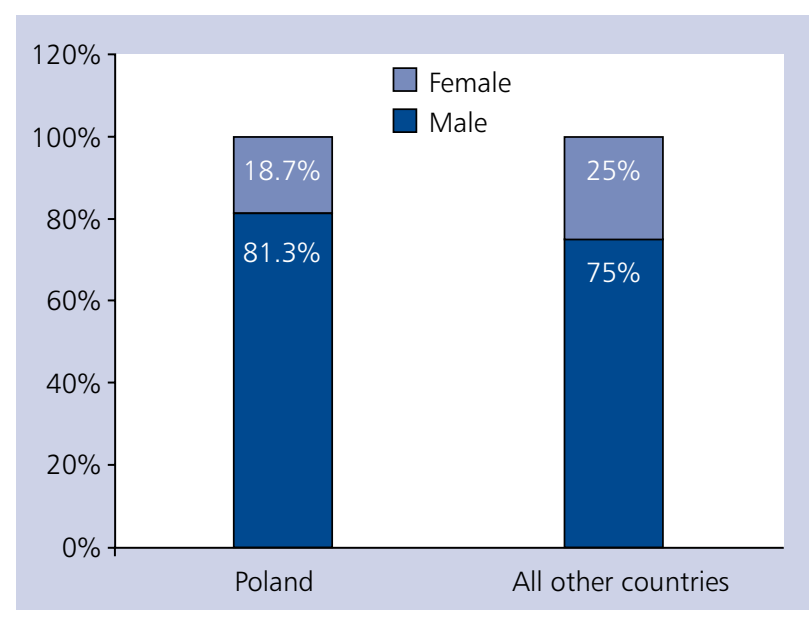

Figure 1. Sex proportions in the analysed populations $(p<0.00001)$

men (Fig. 1). Additionally, 47\% of the total European group had an HF hospitalisation during the previous year.

There were substantial differences in primary aetiology of HF in Polish patients compared to patients from other countries (Fig. 2). More detailed data from the survey revealed that in Poland there were also a greater number of patients with a history of myocardial infarction and prior revascularisation (percutaneous coronary intervention or coronary artery bypass grafting; Table 2) [12].

The EuroHeart Survey showed that persistent and permanent atrial fibrillation (AF) account for approximately $51 \%$ of AF [13]. In the European CRT Survey II, patients with

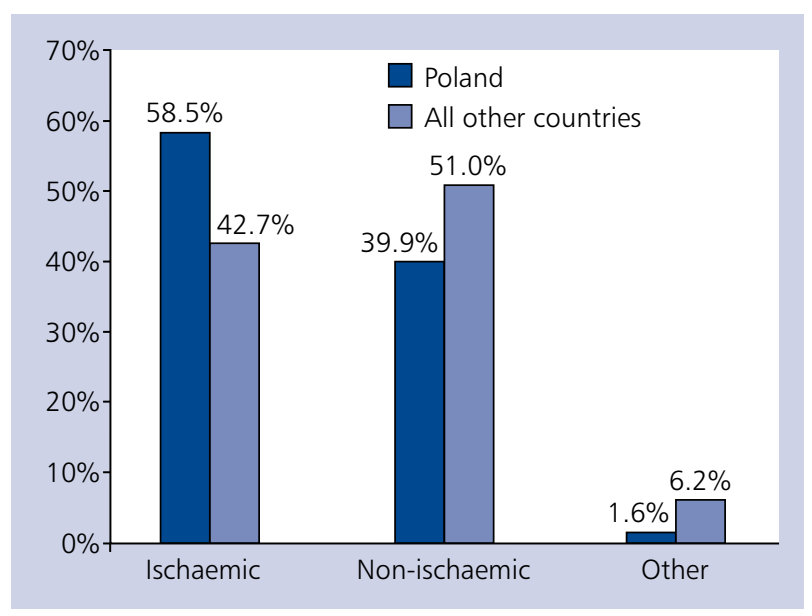

Figure 2. Primary heart failure aetiology $(p<0.00001)$

diagnosed AF formed a large part of the cohort - $43.8 \%$ in Poland and $40.5 \%$ in all other countries, with the rates of persistent and permanent forms at $55.1 \%$ and $67.0 \%$, respectively $(p=0.00024)$.

Patients with CHF tended to have several comorbidities. The management of these is often crucial for successful HF treatment. The major comorbidities occurring in patients with HF and an implanted CRT device are presented in Table 3.

Apart from demographic data and clinical status, another area of interest presented in the European CRT Survey II is indications for device implantation according to the ESC guidelines. The clinical indications for CRT are presented in Table 4. 
Table 3. Major comorbidities occurring in patients with congestive heart failure

\begin{tabular}{|lccc|} 
Comorbidity & Poland & Other countries & $\mathbf{p}$ \\
\hline Hypertension & 68.4 & 63.3 & 0.00041 \\
Valvular heart disease & 32.3 & 26.5 & 0.00002 \\
Obstructive lung disease & 10.0 & 12.3 & 0.019 \\
Diabetes & 37.2 & 30.7 & $<0.00001$ \\
Anaemia & 14.8 & 15.1 & 0.8 \\
Chronic kidney disease (eGFR $\left.<60 \mathrm{~mL} / \mathrm{min} / 1.73 \mathrm{~m}^{2}\right)$ & 36.0 & 30.5 & 0.0078 \\
\hline
\end{tabular}

Data are shown as percentage. eGFR - estimated glomerular filtration rate

Table 4. Clinical indications for cardiac resynchronisation therapy (CRT)

\begin{tabular}{|lccc|}
\hline Clinical indication for CRT & Poland & Other countries & $\mathbf{p}$ \\
\hline Heart failure with wide QRS & 67.7 & 59.0 & 0.0001 \\
Heart failure and indication for ICD & 55.5 & 46.9 & 0.0001 \\
Pacemaker indication and expected high percentage of RV pacing & 22.7 & 22.8 & 0.9385 \\
Evidence of mechanical dyssynchrony & 14.6 & 11.1 & 0.0003 \\
\hline
\end{tabular}

Data are shown as percentage. ICD — implantable cardioverter-defibrillator; RV — right ventricle

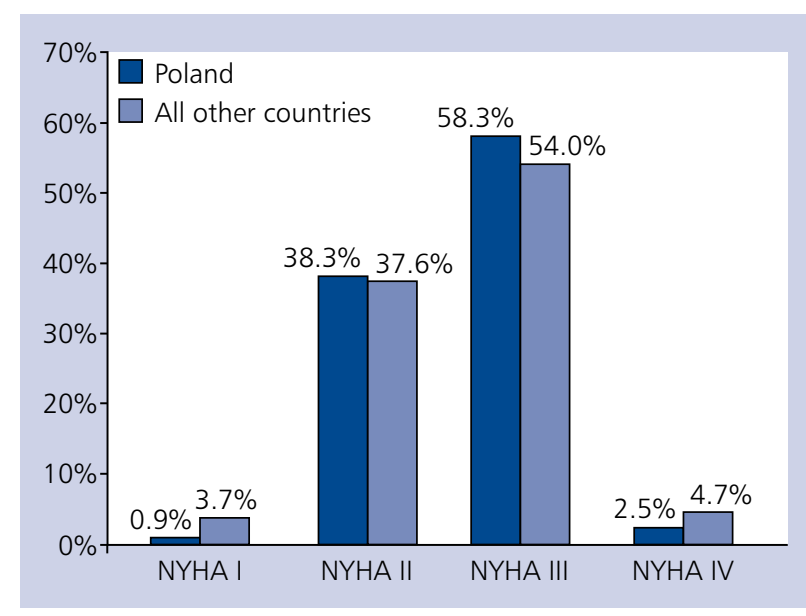

Figure 3. New York Heart Association (NYHA) class in pre-implantation clinical evaluation $(p=0.246)$

Cardiac resynchronisation therapy is recommended for symptomatic patients with HF in NYHA functional class II-IV and a wide QRS. In Poland, $67.7 \%$ of patients (vs. 59.0\% in all other countries) met these criteria, due to the presence of LV dysfunction and indications for ICD because of wide QRS. Additionally, almost $10 \%$ of patients in both compared groups were referred for CRT due to indication for pacemaker and expectation of a high percentage of RV pacing even without HF symptoms (NYHA functional class I) (Fig. 3).

Both in Poland and in other countries, LBBB was present in the majority of patients (Fig. 4). Proportions of pa-

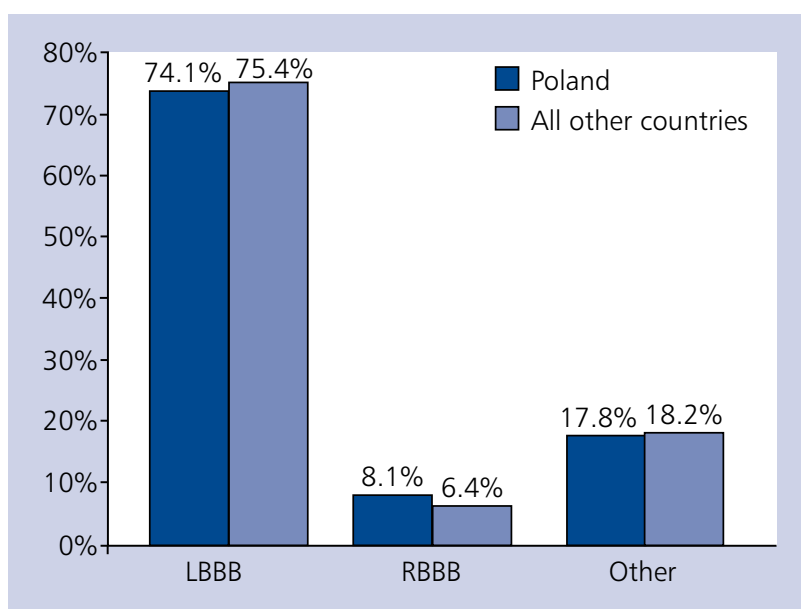

Figure 4. QRS morphology groups; LBBB — left bundle branch block; RBBB — right bundle branch block $(p=0.03336$ )

tients with various intrinsic QRS duration are presented in Figure 5 .

Another parameter of patient evaluation for CRT is LVEF (Fig. 6). According to data collected in the survey, the most popular imaging method assessing LVEF was echocardiography (99.0\% of patients in Poland vs. $91.5 \%$ in other countries, $\mathrm{p}<0.00001)$. However, alternative methods of assessing LVEF, such as cardiac magnetic resonance imaging, computed tomography scan, and scintigraphy, were also used. In Poland, these methods were applied in $1.0 \%$ of patients, and in other countries this rate was $8.5 \%(p<0.05)$. 


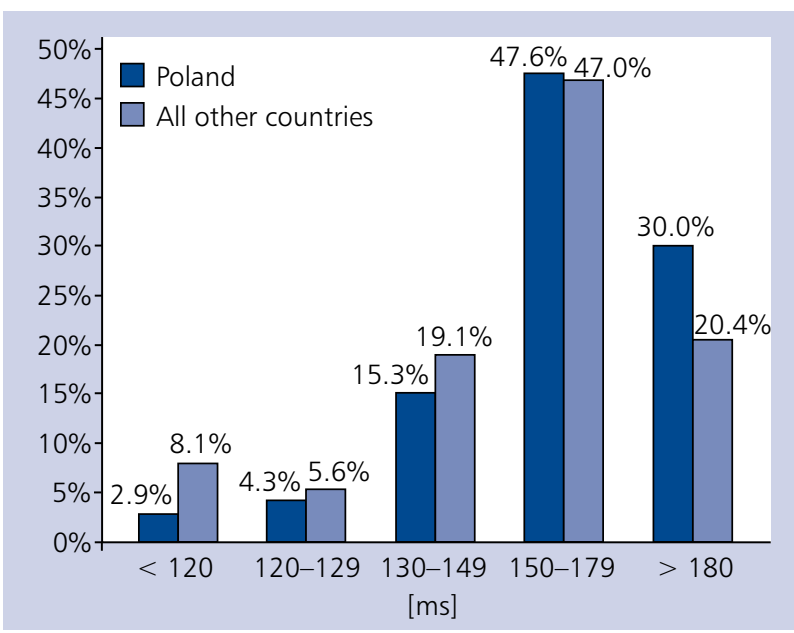

Figure 5. Intrinsic QRS duration $(p<0.00001)$

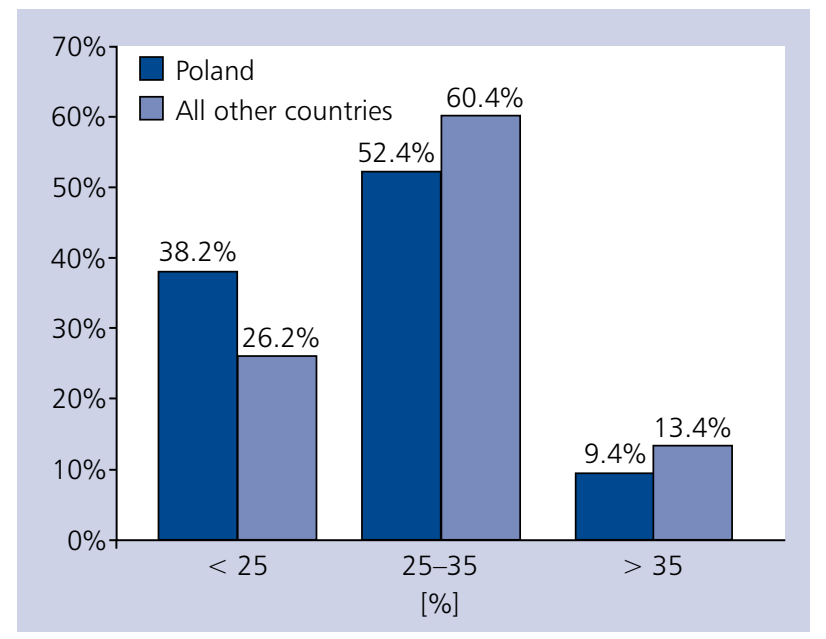

Figure 6. Left ventricular ejection fraction (by any method) measured in pre-implantation imaging $(p<0.00001)$

\section{DISCUSSION}

Patients included in surveys may differ from those enrolled in RCTs due to the distinct methodology of data collection. RCTs have strict protocols concerning patient selection, inclusion and exclusion criteria, and specified outcomes, which is why they include a specific, well-selected group of patients. Conversely, surveys gather a vast amount of data without limitations, demonstrating a wide range of information on selected issues [14].

For Poland, most of the collected data were similar to those obtained from other European nations, but there were also some differences. Compared to patients enrolled in RCTs, Polish patients included in the CRT Survey II were generally older, had narrower QRS complexes, higher LVEF, and more often had AF. However, there was a similar percentage of ischaemic cardiomyopathy and sex proportion [15].
Considering the age of patients included in the survey in terms of the World Health Organization definition of elderly, CRT is a treatment that mostly refers to older people [16].

In both Poland and other European countries, there was a significant difference in the numbers of device implantations in women and men. Women are more likely to experience LBBB and may benefit from CRT at a shorter QRS duration than men [17]. On the other hand, women with HF are older and less likely have severely reduced LVEF [18], which might be the reason why they are much less often referred for CRT device implantation.

In 2013, the ESC in collaboration with the EHRA classified cardiac pacing and CRT patients with persistent and permanent AF as candidates for CRT in their guidelines for the first time. A total of $43.8 \%$ patients in Poland and $40.5 \%$ in all other countries were diagnosed with AF. Persistent and permanent AF accounted for more than a half of this group [19]. There have been no relevant trials that compared CRT to a control group for patients with $\mathrm{AF}$; however, AF has been shown to decrease biventricular pacing in CRT due to competition with irregular intrinsic atrioventricular (AV) conduction [20]. This could possibly diminish the clinical benefits of device implantation, because CRT requires a high percentage of ventricular pacing to maximise its role in HF therapy. The latest guidelines recommend CRT for patients with AF (class Ila) and stress the importance of biventricular pacing (as close to $100 \%$ as can possibly be achieved) either through AV nodal ablation or through pharmacotherapy.

Most patients included in the European CRT Survey II experienced LBBB and an intrinsic QRS duration longer than 150 ms. RCTs meta-analyses have shown that the longer the patient's intrinsic QRS duration, the more beneficial the clinical long-term outcome of CRT implantation [21]. Sub-analyses of RCTs and meta-analyses have shown that the profitable effects of CRT were observed in patients with typical LBBB [22]. Some patients (2.9\% in Poland, $8.1 \%$ in other countries) received CRT even though they had a QRS duration shorter than 120 ms. Current guidelines based on the ECHO-CRT and LESSER-EARTH trials do not recommend implanting CRT in such cases because there is no evidence of benefit in patients with HF and QRS duration shorter than 120 ms [23, 24].

Both in Poland and in other countries, the majority (90.6\% and $86.7 \%$, respectively) of patients had an LVEF of less than $35 \%$. There are only two trials (REVERSE, BLOCK-HF) that enrolled patients with an LVEF greater than 35\%. Due to the small group of patients included, the results were inconclusive.

Despite the large number of patients enrolled in the survey, there were huge differences between countries. In countries with only one or two participating centres, results may be inconclusive for the whole country. Moreover, implanting sites may have neglected patients with poor outcome or unsuccessful procedures, because there was no independent monitoring of data collection. During the enrolment period of the survey the new ESC HF guidelines were published. It is difficult to assess their impact on selection and enrolment of patients. 
In conclusion, as far as demographic data from the survey are concerned, it can be generally inferred that patients receiving CRT were mainly men with depressed LVEF (mostly less than 35\%), LBBB, and an intrinsic QRS duration of more than $150 \mathrm{~ms}$. This was observed for both Poland and other European countries and is in line with the guidance criteria for CRT device implantation.

On the other hand, some devices were implanted in patients with a relatively narrow QRS complex, patients with non-LBBB, and patients with LVEF over 35\%. For these indications, guideline recommendations are weak and levels of evidence are low, and the decision regarding CRT implantation relies mainly on the physicians' experience.

\section{Acknowledgements}

The authors would like to thank Tessa Baak (Norway) for study coordination and extreme support in data management.

\section{Euro CRT Survey II Polish arm contributors list (inclusions per site order)}

Mariusz Gąsior (Zabrze); Piotr Ponikowski, Dariusz Jagielski (Wroclaw); Hanna Szwed, Mariusz Pytkowski (Warsaw); Andrzej Przybylski (Rzeszow); Zbigniew Kalarus (Zabrze); Grzegorz Opolski (Warsaw); Krzysztof S. Gołba, Jacek Wilczek (Katowice); Stefan Grajek, Przemysław Mitkowski, Lidia Michalak (Poznan); Dariusz Wojciechowski (Warsaw); Paweł Czaja (Kalisz); Grzegorz Raczak, Maciej Kempa, Szymon Budrejko (Gdansk); Andrzej Skrobowski, Zbigniew Orski (Warsaw), Marianna Janion, Anna Polewczyk (Kielce); Wojciech Gnyp, Marek Ujda, Jerzy Ozga (Stalowa Wola); Hubert Krupa (Polanica Zdroj); Barbara Pankiewicz, Bogusław Grzegorzewski (Chorzow); Ryszard Grzywna (Lublin); Paweł Jesionowski, Paweł Waloszek, Piotr Anders (Zielona Gora); Jerzy Górny, Tomasz Godlewski (Olsztyn); Dorota Kołodziejska, Anna Mroczkowska (Leczyca); Jacek Lelakowski, Justyna Piekarz (Krakow); Robert Gil, Dariusz Kosior, Karol Król (Warsaw); Grzegorz Skonieczny (Torun); Jerzy Krzysztof Wranicz, Krzysztof Kaczmarek (Lodz); Tomasz Sodolski (Lublin); Katarzyna Mizia-Stec, Wojciech Kwaśniewski (Katowice); Aleksander Goch, Bartosz Topoliński (Bydgoszcz); Antoni Przyprawa (Krosno); Artur Oręziak (Warsaw); Krystyna Łoboz-Grudzień, Mateusz Kuśmierz (Wroclaw); Krzysztof Turuk, Adam Gorlo (Augustow), Paweł Miękus, Elżbieta Dułak (Gdynia); Zbigniew Kiedrowicz, Mariusz Nowakowski (Slupsk); Marek Szołkiewicz, Roman Moroz (Wejherowo); Roman Szełemej, Ryszard Serafin (Walbrzych)

Funding: The European CRT Survey II was supported by the European Heart Rhythm Association, the Heart Failure Association, Biotronik, Boston Scientific, Medtronic, Sorin, St. Jude, Abbott, Bayer, Bristol-Myers Squibb, and Servier.

Conflict of interest: none declared

\section{References}

1. Mosterd A, Hoes AW. Clinical epidemiology of heart failure. Heart. 2007; 93(9): 1137-1146, doi: 10.1136/hrt.2003.025270, indexed in Pubmed: 17699180.

2. Gąsior M, Pyka Ł, Gorol J, et al. COnteMporary Modalities In Treatment of Heart Failure: a report from the COMMIT-HF registry. Kardiol Pol. 2016; 74(6): 523-528, doi: 10.5603/KP.a2015.0224, indexed in Pubmed: 26596896.

3. Cleland JG, Abraham WT, Linde C, et al. An individual patient meta-analysis of five randomized trials assessing the effects of cardiac resynchronization therapy on morbidity and mortality in patients with symptomatic heart failure. Eur Heart J. 2013; 34(46): 3547-3556, doi: 10.1093/eurheartj/eht290, indexed in Pubmed: 23900696.

4. McAlister FA, Ezekowitz J, Hooton N, et al. Cardiac resynchronization therapy for patients with left ventricular systolic dysfunction: a systematic review. JAMA. 2007; 297(22): 2502-2514, doi: 10.1001/jama.297.22.2502, indexed in Pubmed: 17565085

5. Cazeau S, Ritter P, Bakdach S, et al. Four chamber pacing in dilated cardiomyopathy. Pacing Clin Electrophysiol. 1994; 17(11 Pt 2): 1974-1979, indexed in Pubmed: 7845801.

6. Brignole M, Auricchio A, Baron-Esquivias G, et al. 2013 ESC Guidelines on cardiac pacing and cardiac resynchronization therapy: the Task Force on cardiac pacing and resynchronization therapy of the European Society of Cardiology (ESC). Developed in collaboration with the European Heart Rhythm Association (EHRA). Eur Heart J. 2013; 34(29): 2281-2329, doi: 10.1093/eurheartj/eht150, indexed in Pubmed: 23801822.

7. Sterliński M, Maciag A, Kowalski O, et al. Mortality in patients with heart failure treated with cardiac resynchronisation therapy. A long-term multi-centre follow-up study. Kardiol Pol. 2007; 65(11): 1287-1294, indexed in Pubmed: 18058579.

8. Abraham W, Fisher W, Smith A, et al. Cardiac resynchronization in chronic heart failure. N Engl J Med. 2002; 346(24): 1845-1853, doi: 10.1056/nejmoa013168.

9. Dickstein K, Normand C, Auricchio A, et al. CRT Survey II: a European Society of Cardiology survey of cardiac resynchronisation therapy in 11088 patients - who is doing what to whom and how? Eur J Heart Fail. 2018; 20(6): 1039-1051, doi: 10.1002/ejhf.1142, indexed in Pubmed: 29457358.

10. Linde CM, Normand C, Bogale N, et al. Upgrades from a previous device compared to de novo cardiac resynchronization therapy in the European Society of Cardiology CRT Survey II. Eur J Heart Fail. 2018; 20(10): 1457-1468, doi: 10.1002/ejhf.1235, indexed in Pubmed: 29806208.

11. Dickstein K, Normand C, Anker SD, et al. European cardiac resynchronization therapy survey II: rationale and design. Europace. 2015; 17(1): 137-141, doi: 10.1093/europace/euu312, indexed in Pubmed: 25414481.

12. Tymińska A, Balsam P, Ozierański K, et al. Heart failure patients with a previous coronary revascularisation: results from the ESC-HF registry. Kardiol Pol. 2018; 76(1): 144-152, doi: 10.5603/kp.a2017.0181

13. Nieuwlaat R, Capucci A, Camm AJ, et al. Atrial fibrillation management: a prospective survey in ESC member countries: the Euro Heart Survey on Atrial Fibrillation. Eur Heart J. 2005; 26(22): 2422-2434, doi: 10.1093/eurheartj/ehi505, indexed in Pubmed: 16204266.

14. Gitt AK, Bueno H, Danchin N, et al. The role of cardiac registries in evidence-based medicine. Eur Heart J. 2010; 31(5): 525-529, doi: 10.1093/eurheartj/ehp596, indexed in Pubmed: 20093258.

15. Wells G, Parkash R, Healey JS, et al. Cardiac resynchronization therapy: a meta-analysis of randomized controlled trials. CMAJ. 2011; 183(4): 421-429, doi: 10.1503/cmaj.101685, indexed in Pubmed: 21282316 
16. WHO, Geneva: Switzerland; 2010. World Health Organization. Definition of an older or elderly person. http://www.who.int/healthinfo/survey/ageingdefnolder/en/index.html.

17. Zusterzeel R, Selzman KA, Sanders WE, et al. Cardiac resynchronization therapy in women: US Food and Drug Administration meta-analysis of patient-level data. JAMA Intern Med. 2014; 174(8): 1340-1348, doi: 10.1001/jamainternmed.2014.2717, indexed in Pubmed: 25090172.

18. Linde C, Ståhlberg M, Benson L, et al. Gender, underutilization of cardiac resynchronization therapy, and prognostic impact of QRS prolongation and left bundle branch block in heart failure. Europace. 2015; 17(3): 424-431, doi: 10.1093/europace/euu205, indexed in Pubmed: 25164429.

19. Ozierański K, Kapłon-Cieślicka A, Peller M, et al. Clinical characteristics and predictors of one-year outcome of heart failure patients with atrial fibrillation compared to heart failure patients in sinus rhythm. Kardiol Pol. 2016; 74(3): 251-261, doi: 10.5603/KP.a2015.0180, indexed in Pubmed: 26365943.

20. Cheng A, Landman SR, Stadler RW. Reasons for loss of cardiac resynchronization therapy pacing: insights from 32844 patients. Circ Arrhythm Electrophysiol. 2012; 5(5): 884-888, doi: 10.1161/CIRCEP.112.973776, indexed in Pubmed: 22923341.
21. Sipahi I, Carrigan TP, Rowland DY, et al. Impact of QRS duration on clinical event reduction with cardiac resynchronization therapy: meta-analysis of randomized controlled trials. Arch Intern Med. 2011; 171(16): 1454-1462, doi: 10.1001/archinternmed.2011.247, indexed in Pubmed: 21670335.

22. Zareba W, Klein H, Cygankiewicz I, et al. Effectiveness of Cardiac Resynchronization Therapy by QRS Morphology in the Multicenter Automatic Defibrillator Implantation Trial-Cardiac Resynchronization Therapy (MADIT-CRT). Circulation. 2011; 123(10): 1061-1072, doi: 10.1161/CIRCULATIONAHA.110.960898, indexed in Pubmed: 21357819.

23. Thibault B, Harel F, Ducharme A, et al. LESSER-EARTH Investigators. Cardiac resynchronization therapy in patients with heart failure and a QRS complex <120 milliseconds: the Evaluation of Resynchronization Therapy for Heart Failure (LESSER-EARTH) trial. Circulation. 2013; 127(8): 873-881, doi: 10.1161/CIRCULATIONAHA.112.001239, indexed in Pubmed: 23388213.

24. Steffel J, Varma N, Robertson M, et al. The effect of QRS duration on cardiac resynchronization therapy in patients with a narrow QRS complex: a subgroup analysis of the EchoCRT trial. Eur Heart J. 2015; 36(30): 1983-1989, doi: 10.1093/eurheartj/ehv242, indexed in Pubmed: 26009595.

Cite this article as: Łasocha D, Sterliński M, Tajstra M, et al. Do we differ in terms of indications and demographics in cardiac resynchronisation recipients in Poland? Insights from the European CRT Survey II Registry. Kardiol Pol. 2019; 77(1): 40-46, doi: 10.5603/KP.a2018.0215

\section{WHAT IS NEW?}

In 2015 and 2016, Polish implanting centres participated in the second edition of the European Cardiac Resynchronisation Therapy Survey. For 14 months, European centres gathered a vast amount of data regarding demography, indications, implanting methods, and guidance compatibility from patients with congestive heart failure receiving cardiac resynchronisation therapy. The survey was designed to describe clinical practice regarding implantation of cardiac resynchronisation therapy in a broad sample of hospitals in the European Society of Cardiology member countries. The results enabled an assessment of guideline adherence and demonstrated variations in patient selection, management, implantation procedure, and follow-up strategy. What is more, the survey provided data permitting centres and countries to benchmark their practice with national and international practice. 